\title{
On a new curative pharmacon of the atrophic Rhinitis.
}

\author{
By \\ Tanyo Sada.
}

From the Oto-Rhino-and Laryngological clinic of the Kyoto Imperial University.

(Director: Prof. T. Hosinno).

The so-called Ozena-problem still remains unsolved despite the fact that it has been discussed among medical men for quite a long time. The cause as well as pathology of the disease is not yet clear, with the result that remedical methods hitherto tried, though too numerous to be mentioned had been discarded as ineffective. Nowadays two most popular treatments of ozena are in vogue in rhinological circles, viz:-

1. A method aiming at narrowing the inside area of the nasal cavity by means of a surgical operation as well as a submucous injection of Paraphine.

2. A vaccine treatment which, aftirming the Coccobacillus foetidus Ozaenae as a cause of the disease, is performed through a causeremedy. Advocators regarding both of these two methods as effective are not few but increasing in number.

'These methods, however, though diverse in their applications and proving to be more or less successful, not only are unable to be carried on with the same degree of efficiency, but also often end in failure, and sometimes meet with cases almost impossible to be performed. Even some of the practitioners who insist on this Vaccine-theory admit that the surgical operation, i. e, transplantation of other anatomies to the mucous membrane and the Paraphine injection, etc. are only effective while the responsive inflammation caused by the operation and injection lasts; consequently, with the disappearance of this operative reaction the indisposed feeling which the patient had before the operation reappears.

With regard to the Vaccine-method, the bacillar theory of Perez, the pros and cons of which are to-day still equally divided, cannot be said to 
be absolutely corroborated. Therefore, we are justified in saying that the value of the Vaccine-treatment method is still an unknown quantity. Moreover, adequate facilities and equipment are required for the production and storage of the Vaccines which an ordinary dispensary cannot afford Besides, as this treatment-method not only causes an exceptionally high fever of 38-39 degrees or thereabout, but it takes a considerable length of time (nearly five to eight months), and it cannot be effectively carrived on without special patience and exertion on the part of the patient. These are inconveniences and defects in this method, when practically considered.

It has been reported by Drs. Dem, Styl, Demetriades, and Dr. Constantine Mauloussis, that 46 out of 100 cases under this Vaccine-treatinent were of good effect; 24 were discontinued on account of the patients' absence, and 18 proved to be utterly ineffectual. Concerning the ineffectual cases, the three following reasons are given as being the most noticeable:

1. Considerable height of flabliness.

2. Imperfection of continuation of the injections, owing to the irregularities of the patients' coming.

3. Either the irregularities of rinsing out and cleansing of the insidenose, or an entire lack of it.

Elemer Pollatschek, in his reports of 24 cases of the Vaccine-treatment (1914-21) declares that the majority of the cases have been cured and the rest greatly improved. But he adds, "It would be still better to perform either surgical operations or Par,tphine-injections upon the affected sections after the Vaccine-healing has been tried." These words of his make us perceive that he, while advocating the Vaccine-theory on one hand, is contradicting hinself in endorsing on the other the scantiness of value of the Vaccine-treatment.

Whether the cause of the disease be the Bacillus discrvered by Perez or not, I thought if there was not some other chemical or Materia-media healing methods capable of being carried on clinically more effectively, and for the past several years have searched for many sorts of medicines and used them, but without success. For instance, for venous-injections I used physiological salt-water and its dense liquid, Calcium, Iodium, Chinine and its conductor, Grape-juice, heavy metalic salt and its coloid preparations 
and Salvarsan. Besides these Vitamins A. B. C. or preparations of the endocrin (i. e. of the thymus gland, thyroid gland, and pituitary body); and esf ecially, a hormon medicine used for diseases of testicles and ovaries were tried, but in vain, Lastly, I tried pigmentary medicines. However, most of the medicines of these kinds which are used for chemical healings are of a poisonous nature, I used first of all Trypaflavin and Rivanol, which Morgenroth named "Chemical disinfectants," but these also showed no conceivable effect on the affected parts. However, my strong expectation was that such medicines as these, which have disinfection power, nust have some influence upon such diseases as those whose intensity of putrefaction is considerably high, so that I could not bear to give up these medicines entirely.

Consequently, I started another chemical research in every possible way with the Akriden pigment which is the basis of the two medieines mentioned, and after many failures, finally succeeded in discovering a new medicine, which, upon being tried on diverse diseases of the Atrophic Rhinitis, has shown an interesting result beyond my expectation. Hereupon, I am making this result of my experiments known, and would ask for any criticisms of scholars at large.

I have named this medicine "SAFLAVIN." Its chemical structure is not yet fully known. It may perhaps be rightly called "Magnesiumdimethylamino Akridium Chloride." It is a lustrous ingot of a dark brown colour and has a sticky nature, unable to be easily pulverized; souluble in heat of 120 degrees; in a normal temperature, insoluble in ether, slightly soluble in alcohol, easily in water. Its solvent presents a slight acid or neutral reactions, and it is odourless and refreshing, but has a little bitterness. I omit here miuute descriptions of its recipe as well as chemical naturs, and will try to make a precis of its poisonous nature instead.

When 10 c.c. of the Saflavin-solvent at the rate of $5 \%$ is injected into the skin of a rabbit weighting circ. $1.5 \mathrm{~kg}$., the breathing of the animal becomes gradually slow and after half an hour or so its hind legs get paralyzed. But after the lapse of 5 or 6 hours they are gradually recovered and no special changes are perceived. 
If $20 \mathrm{c}$ c. of the $5 \%$ solvent is injected into the ear-veins of rabbits, each $1.5 \mathrm{~kg}$. in weight, they become instantly inactive, fall into a comatose state in a few hours and half of them will soon die. 'The survivors recover from the poisoned conditions and begin' to have an appetite after two days; the third day nothing seems to ail them at all. Next, when 15 c. c. of the $5 \%$ solvent is injected into the ear-veins of sonıe rabbits of the same weight, they, though highly poisoned for some hours, in twelve hours gradually regaia consciousness and none of them die.

The conclusion is :-

The death-cause quantity (Dosis, toxica letalis) of the Saflavin against a rabbit weighing $1 \mathrm{~kg}$. is 0.6 grams. Therefore, if this rate is converted to $50 \mathrm{~kg}$., which is an average weight of the adults body, the death-cause quantity (poris toxica letalis) of the Saflavin against a human body amounts to 3.0 grams. Again, when I c. c. of $1 \%$ Solvent is injected into the ear-veins of a rabbit every day or every second days, successively from 40 to 60 times, no poisoning happens and the animal lives and is as active as ever. Namely, in these successive injections at an interval of one day or two, the total quantity amounts to 0 4-0 6 grans, but it shows no such signs in the animal as slowness of breathing or paralysis of the limbs as when 10 c.c. of the $5 \%$ solvent is injected at one time. Accordingly, it is evident that this medicine works no accumulation. Moreover, examinations of the poisonous power of it with mice and mormot-rabbits proved to be substantially of the same result. In fine, the biological nature of the Saflavin is, compared with that of Trypaflavin or Rivanol is far milder, and according to my experinents, the healiug-quantity (10 c.c. of its $3 \%$ solvent, i. e. one hundredth of the death-cause quantity) which I am using for an adult, seems to cause no perceivable harm.

\section{Applied healing-treatment:}

In the healing-treatment with the Saflavin an intravenous injection seems to be the best way. But when this is difficult to be carried on either a hypodermic injections only, or sometimes uenous and hypodermic injections alternately can be carried on periodically. In case of the venous injection a mild warmth is felt all over the inside nose, throat and chest. 
But this soon disappears. At the time of the hypodermic injection (chiefly into the upuer arm at the rate of 2 c. c. of the $5 \%$ solvent) a slight incentive pain in the section and a little dulness in the hand are felt, but these also disappear in a few hours and cause no changes in the section. Some persons may for several days feel a slight press-pain, owing to a lump caused in the section by the injection, but this also gradually disappears, causing no such harm as an ulcer or an incised wound etc. There is no fever caused by this injection, and internal medicines can be taken with impunity.

\section{Instances of Healing :}

Of 28 instances, 10 are men and 17 are women; ages, 10-40 years. Since the invasion of the disease, some elapsed a period of 15-16 years; four months at the shortest. Thirteen of these instances are of a genuine Orena (a nose-inflammation of an offensive smell). Fifteen are simple Atrophic Rhinitis. Ten are complicater with arid throat-inflammation. 'T'wo are concurrent with a larynx-Ozena. Five instances of thore whose antrums had been already radically operated upon. Four instances, already received paraphine-injections or trancplantations. One instance had formerly had a chiselling out of the ethmoidal cells.

In the case of genuine Ozenas, the Wassernan's reactions are all negative. Two instances showed as the result of an explaratory-puncture of the maxillary antrum, an existence of a moderate quantity of viscous pus. Thirteen instances proved an existence of a small quantity of a viscous liquid. 'Two instances found a yellow and transparent serum. Eight instances showed an entirely negative reaction.

\section{Continuation of Injections :}

From five to thirty-five times every day, or every two days. The majority ended with 20-25 injections, and thirty times were counted one "cur."

In the course of the treatment no other measures were taken for the affected sections of the nose in order to clarify the efficiency of the Saflavin except washing them, sometimes with $3 \%$ sola-water, when found necessary. 


\section{Summary of the Results of Treatment:}

Of the genuine Ozenas, 5 cases showed convalescence;' 2 no change. Of the simpler ones, 3 were perceived to be entirely cured, 9 showed convalescence, and 2 no change.

To state these in percentage:

15\% showed no change: $85 \%$ were either entirely healed or very much improved.

\section{Curative Progress :}

Some are greatly improved with two or three injections, but in most cases, from the sixth or seventh injection, secretions, as well as crusts decrease and easily excreted, with the result that the feeling of nosestuffiness becomes very much lessened. Also, the profuse nose-bleeding. hitherto happening, stops, and headache, dizziness, dullness, spiritlessness, weakened memory, and sleeplessness which are caused by the prostration of the nasal-nerves are almost gone, and the odor inside the nose disappears. With the tenth injection the inside-nose becomes abjectively clean, the arid excretion decreases in its quantity, partaking of a tough nature: the surface of the mucus-membrane becomes smooth and glassy and comes to show a humid nature, and even if it should be robbed violently with a tampon-holder there is no bleeding as before, and the secretion has almost no odor.

As to the convalescent velocity of the disease, each instance does not necessarily progress at the same rate of speed, and even if the nostrils should be remarkably enlarged and widened, that which has a high degree of toughness of its secretion is narrowed by it, and the grade of atrophy is usually low; and it has a tendency to be more easily cured thau those having high degrees of aridness of their secretions. Speaking sectionally, the nostrils are healed first, then the throat, and the larynx Ozena seems to be the most lenacious one.

\section{Some instances of the disease, able to be regarded as the most representative.}

I. A hiyh Echool boy, 18 years of age: parents healthy: brother and sister with no nose disease: no remarkable illness in the past. 
Course of the disease: For six years he had much secretion of the nose, had been usffering from stoppage of the nose and pharynx aridness, also headache and dullness of memory; consulted a country doctor but saw no improvement: came up to Kyoto and was operated on the antrum and was some time convalesing. But after three months he gradually camc to feel indisposed again, and since that time, for about three years, he has suffered from excessive nose bleeding. Following the doctor's advice he managed to stop further progress of the disease by means of washing and suffising menthololiveoil into the inside-nose. For about two years there was no change in the development of the disease, but since winter before last the secretion of the nose has become arid and simultaneously the odor returned. So again the doctor prescribed washing and suffusing daily. Through this treatment he gained some relief during the past summer, but with the coming on of the cool autumn weather the disease developed, viz, the crusts became considerably larger and tube-shaped; hardly able to be excreted withont much bleeding, and which could be removed only wiih much difficulty, by washing with special care. From this time on the odor became so intense that other students in the same room in the school dormitory came to dislike his company and ostracise him. Besides, headaches and sleeplessness increased day by day. Therefore the poor boy became exceedingly melancholy, till at length he began to curse this tenacious disease and to lament of his misfortune. He then tried to keep himself away from his fellow students as much as possible. However, at last, having found that the odor, unless the nose be constantly washed would pervade the whole room, he called at my dispensary, sad and forlorn.

Symptoms: Moderate both in constitution and nutrition: no abnormal signs in his countenance except paleness to some extent: spiritless in his actions: melancholy in his emotional expressions. The shape of his nose is normal and not saddle-like.

Through the Rhinoscopia anterior it has been found that the nostrils are greatly enlarged: that, extending from the upper surface of the strophied concha-inferior to the septum of the middle nasal duet, some green crusts of a half-tubed shaje are found sticking, which, when picked or dragged out with a pincette, emit an offensive odor. The concha-media leaves no trace whatever and the mucons membrane is congested, and has a coarse surface, and in various parts of the concha is bleeding backward. The pharynx is intensely arid and shining, and secretion of a yellow colour is sticking, unable to be easily disgorged. In one of the nostrils, some parts of the surface of the septum is seen bleeding.

The Rhinoscopia Posterior shows that crusts are sticking in pieces here and there from the concha to the pharynx-canopy: the larynx is somewhat congested, but no special change is to be seen on it. Nothing aila the ears. The W-reactions are negative.

Diagnosis: A genuine Ozena, together with a Larynx-inflammation of an arid nature.

Treatment: Every day the affected section washed with $3 \%$ soda water and 1 c. c. of the $3 \%$ Saflavin injected into the veins. These lasted for three days. The third day, the patient becamc a little cheerful, owing to the decrease of headaches, On the seventh day the crusts 
had greatly decrersed and the secretion also had diminished to a large extent. Only a little blood found mingled in the secretion: the odor (foctid) abated. On the 11th day, no more bleeding: the crusts had become less: secretion which had to be blown ont over ten times a day had so much decreased in quantity that it had to be blown out only twice a day : headaches gone: memory restored, and the odor almost disappeared.

On the 20 th day all the affected parts were greatly improved and the patient was able to attend to his schoul work, in high spirits. Objectively perceived, the inside of the nose had become considerably eleaner and the secretion had all gone, though some crusts were still found, which, however, could be easily taken out without cansing bleeding. In the larynx some secretion was found sticking, but no crusts were found.

With the 31st injection the treatment was stopped. Since then almost six months have elapsed, and through correspondence with the student $I$ hare learned that no signs of the trouble have appeared.

II. A man of twenty years of age, who is a partner of a drygoods store. Nothing particular is to be recorded concerning his blood relationship. No remarkable diseases in the past.

Course of the Disease: Begin the physical constitution: moderate in nutrition, slightly saddle-nosed: the ears all right. When the inside-nose was examined the nostrils were, found to be largely widened, the mucous membrane engorged all over and its surface rather coarse. Both the middle and inferior turbinals (concha) somewhat atrophied: the lower nasal duet filled with sticky secretion of a vellow pus-like nature, which however has no bad odor. When sounded with a sounder the operation hole was seen perfectly open to wards the wall of the antrum. As a result of the Rhinoscopia Posterior some small crusts were to be seen in the larynx and canopy. The larynx was moist and in a chronic catarrhal condition.

Diagnosis: An Ozena of a simple nature.

Treatment: No measures taken toward the inside-nose. 10\% of Saflavin injected once a day. After the third injection convalescence began and at the fifth injection the patient was entirely curetl.

III. A Kindergarten teacher, a woman of 20 years of age. Nothing particular to be described concerning her relationship and her past diseases.

Course of the Disease: Last September she had a cold, took medicine for a week and recovered. But since then her voice had grown hoarser day by day. She felt something unusual in her larynx, and was treated by a neighbouring doctor for about forty days, but with no good effect.

Symptoms: Moderate both in her physical constitution and nutrition. Nothing unusual is perceptible in other parts of her body. The ears are both sound. Through an examination 
of the inside nose it was found:- the nostrils widened and enlarged to some extend: the turbinals not so big: the mucous membrane was dry all over, but no unclean secretion was seen: the back wall of the pharynx could be seen through, The pharyns walls were also dry and shiny, but no crusts were to be seen.

The result of the Rhinoscopia Posterior: Some dry secretion of yellow pus was seen sticking between the backward edges of the turbinals and the brims of the choana.

Upon examination of the larynx the surface of the mucous membrane was found coarse, congested and dry: and in the false vocal chord a small quantity of yellow crust-like secretion was sticking. The genuine vocal chord was white and thick, but its motion was free.

Diagnosis: A Simple Ozeua, a larynx catarrh.

Treatment: As the patient had no affection of the nose and pharynx no attention was paid to them. $3 \%$ soda water was suffused in the larynx, and the patient was treated with an inspirator. 10 c. c. of $3 \%$ Saflavin was injected into the veins on the first day, and afterward injected every second day. At the fifth injection the patient told me that she could use her voice with some ease, but no remarkable improvement was observed. At the eighth injection utterances in daily conversation became perfectly easy, but still some difficulty was felt in singing. At the twelfth injection the voice gradually became normal and at the sixteenth almost recovered. The injections were stopped with the twentieth. There has been no trouble since.

IV. A girl student: age 19: larents bealthy: no nose-diseases found among her relatives: no special diseases in the past.

Course of the Disease: She had been feeling a nose-plugging for five years. Much secretion of mucus mingled with crusts and sometimes accompanied by an odor: headaches in the forehead increasing year by year, especially felt strongly in winter. Treated often by doctors in various places, but no improvement whatever. Recently no odor detected.

Symptoms: The ears O. K., a saddled nose in a pretty high degree. The result of the Rhinoscopia: the inferior turbinals on both sides. Were perceivably atrophied: some pus-like secretion lodged in the lower nasal duct which, when wiped out, emitted a strong odor, mingling with some small crust-like lumps. The middle turbinal on the right side was pretty thick. The middle turbinal on the left was in an atrophied condition and on its surface some small crusts were sticking. The motion of the back wall of the pharynx could be seen through. The mucous membrane of the pharynx was moist. The larynx was in normal condition.

Through an exploratory puncture of the maxillary antrum a small quantity of mucus was found on the right side, but the left side proved to be negative in its nature. The Wreaction was negative. 


\section{Diagnosis: A Genuine Ozena.}

Treatment: Cleansing of the inside-nose with $3 \%$ soda water. Daily injections of $3 \%$ Saflavin at the rate of 10 c.c.

At the fourth injection the snivel began to partake of' a watery nature and the feeling of the nose-plugging became greatly lessened. At the seventh, no more headaches: secretion also considerably decreased, but the odor (foetid) hither to unnoticed, reappeared, together with an easiness of the nasal-breathing. At the tenth, every symptom of the disease commenced to disappear and the odor was gone altogether. This is perhaps due to the fact that though the odor (foetid) which had been unnoticed for a time, owing to an anosmia respiratria, appeared again: through the healing of the sniffing part caused by the repetition of treatments the nature of the secretion changed and deodorized. And this fact can be reckoued as one of the virtues of the medicine concerned.

The patient went back to his native place after the twentieth injection.

V. A girl of 19 years of age: born in a grog shop family: parents, brothers and sisters all healthy. no inherited diseases nor past diseases.

Course of the Disease: Since her childhood she had much secretion from the nose, which, from her sixteenth year had turned into a yellow pus like nature, hard to excrete, sticking to the nasal pharynx. Consequently she had suffered from a nose plugging which caused depression. An odor (foetid) was detected now and then. Latterly aridness of the pharynx often occurred and for two months a timitus and an auditory difficulty accompanied it. She consulted several doctors in Tokyo and Kobe, but had not improved.

Symptoms: Moderate both in her physical constitution and nutrition. No disease perceptable in the viscera. The Rhrinoscopia showed that both the middle and inferior turbinals were atrophied, in a moderate degree, and the mucous membrane was pale and not so arid. The back wall of the pharynx could be seen through : the mucous membrane of the pharynx was moist: the larynx was in a normal state: no change in the ears excepting a slight subsidence of the ear drums.

\section{Diagnosis : A simple Ozena and a catarrh of Juba Austachii (Eustachian Tube)}

Treatment: Sectionally no measures were takeh towards the nose and the ears: daily venous injection of $2 \mathrm{c}$ c. of $10 \%$ solvent. At the third injection, the secretion decreased and the tinnitus, as well as the auditory difficulty, began to diminish. At the sixth the secretion became snivel-like and was no longer of a pus like nature. The tinnitus entirely stopped and the auditory sense also considerably recovered. From this time the patient felt great relief and improved day by day, and after the 35th injection went home. The reason that so many treatments were given is that the patient, in view of the fruitlessness of the former treatments received in various places, asked for a complete recovery before being dismissed 
from my dispensary. That the tinnitus and the difficulty of hearing (which were unable to be cured by an air-douche) were cured without any measure taken, simply by the injections of Saflarin, is due I believe to the fact that the catarrh of the Eustachis tube, which had been influenced greatly by the nose-disease together with the convalescence of the latter, took a curative turn

VI. A farmer girl, 18 years of age, who had had no illness except a slight attack of dysentery in her fifteenth year.

Course of the Disease: After having caught cold some years ago she began to have much secretion from her nose, which, though treated by a country doctor could not be healed. For the past six months the secretion has increased in quantity, sometimes emitting an odor, and at the same time a strong nose-plugging, and headache in the forehead accompanied. For the past two years much crust has been found and bleeding has often occurred. The sniffing sense has been somewhat injured. Also, the patient had an unusual feeling her pharynx. Having diagnoxed the disease as what we call "empyema," she called at my dispensary to be operated upon.

Symptoms : Stont constitution: moderate nutrition: rather inclined to obesity : no ailment in the viscera: Saddle-nosed to a pretty high degree. The Rhinoscopia shows that the nostrals had enlarged greatly. The inferior turbinals on both sides perceivably atrophied: The middle turbinal on the left side had become twice its natural thickness, while that on right had gone, leaving its trace only. The mucous membrans was congested from the the middle duct to the protuberance of the pharynx and its back wall, which, if taken away, bled. The lower nasal duct was filled with a pus-like secretion. The tonsils on both sides had been enlarged. The entrance of the pharynx was covered with a granula and was moist, By means of chiscelling out the ethmoidal cells only a little mucous could be taken out. The W-reaction was negative.

Diagnosis: A Genuine Ozena.

Treatment: Cleansing the inside-nose with soda water: a daily intravenous injection at the rate of $10 \mathrm{c}$ c. Saflavin.

At the third injection the sniffing sense became active and the nasal breathing became easy. At the 10th the crusts decreased to almost one-third. The odor (foetid) was sometimes detected and sometimes not. The nose cleansing has been stopped.

At the 15th, the secretion decreased to half of its usual quantity, but some crusts were still found sticking here and there. The offensive odor was nearly gone. The headaches stopped. Even when the nucous membrane was rupped with a tampon-holder no bleeding occurred. 
At the 17th, the inside-nose was still unclean and the crusts were not yet entirely gone. Much pus-like secretion was still found, but it could be easily excreted and was nearly deororized.

Objectively considered, the disease had not been absolutely cured by the treatments. However, the patient herself seemed to feel as if the disease had about subsided and she went back to her native place with deep gratitude.

After a lapse of four months $I$ wrote to her inquiring about her condition and her reply was that the disease had taken a favorable turn since her return home, and that she was getting along nicely.

In the foregoing paragraphs I have mentioned some instances where Ozenas has been cured, which I regard as most representative. Having thought it unnecessary to give more descriptions of other cases treated or cured at my dispensary, by means of the Saflavin, I have inserted them in the accomplanying table of those cases I have treated.

Here in conclusion I want to remined my readers of the following points :-

I. Characteristics of the Medicine.

1. Simpleness in its use.

2. It causes no collateral effect on the whole body of the patient.

3. Compared with the Vaccine-treatment it requires a for shorter period for healing the disease.

4. It can be used together with any iuternal medicines.

5. It can be applied both to intra-venous and hypodermic injections.

II. Defects of the Medicine.

1. In case of an hypodermic injection a pretty big quantity (i. e. 3 c.c. at one time) is needed, and also a long continuation of the injection is required.

2. Sometimes it causes, though slightly, an incentive induration in the injected section.

3. When taken internally it is not efficacious 
The above mentioned are merits and demerits of the medicine concerned, and further uses and applications of it are conditioned by our investigations.

As it has not been long since I began to try healing by means of Saflavin the number of healed instances is still small. I can hardly make any ascertainment as to the continuity of its healing effect, as well as its absolute value. In view of the fact however, that this medicine has a special function for improving the condition of Ozena diseases and the like, both objectively and subjectively, I am fully convinced that, at the present time when no other absolutely recognized healing methods for these diseases have been discovered, the medicine concerned can be recommended to be widely used in medical circles.

Concerning the cause of the efficacy of this medicine, it shall be marle public after further investigation thereof.

\section{Iiteratur.}

I) Demetriades u. Moutoussis Festschr. Haijek. 1921.

2) Pollatschek, Festschr. Haijek, 1921, S. 1529.

3) C. morishima, Arzneimittellehre. VII. auflage.

4) C. Funk, die Vitamine. 1922. 5) Kabert. Intoxikationen 2. Band 1916.

6) Ernst Laqueur, Die neueren chemotherapeutischen Präparate aus der chininreiche und aus der Akridinreiche. 1923. 


\begin{tabular}{|c|c|c|c|c|c|c|c|c|c|c|c|c|c|}
\hline 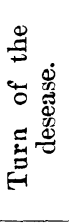 & 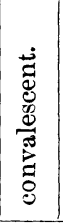 & 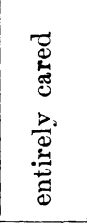 & 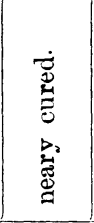 & 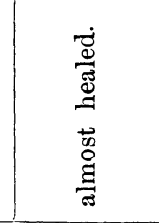 & 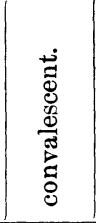 & 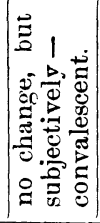 & 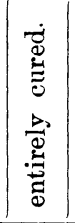 & 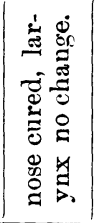 & 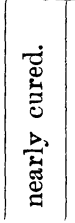 & 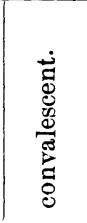 & 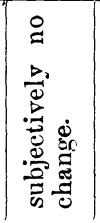 & 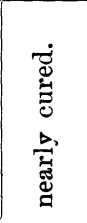 & 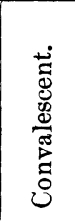 \\
\hline 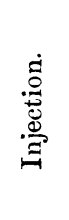 & 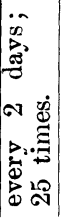 & 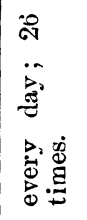 & 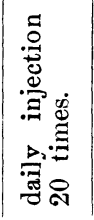 & 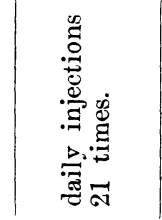 & 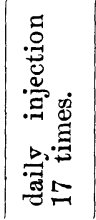 & 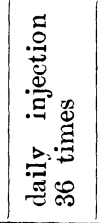 & 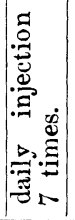 & 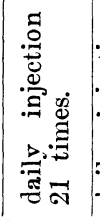 & 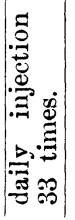 & 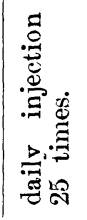 & 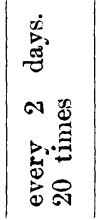 & 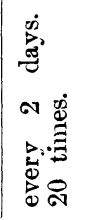 & 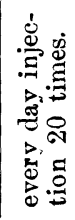 \\
\hline 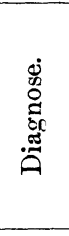 & 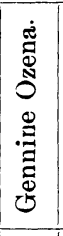 & 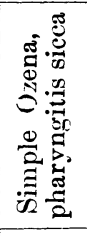 & 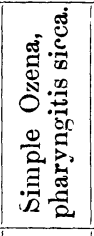 & 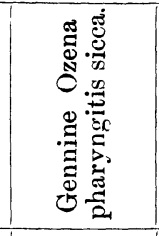 & 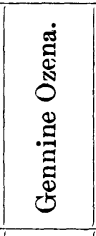 & 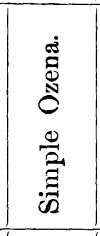 & 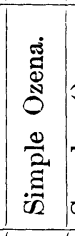 & 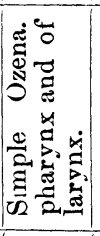 & 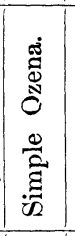 & 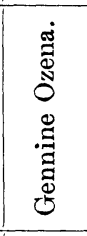 & 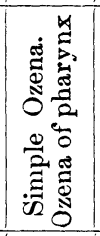 & 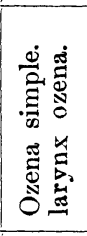 & 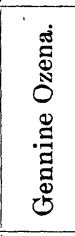 \\
\hline 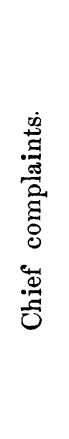 & 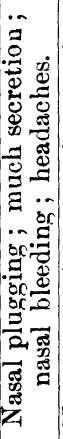 & 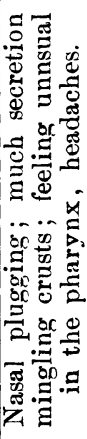 & 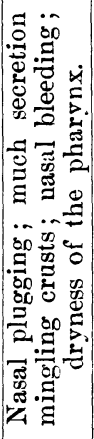 & 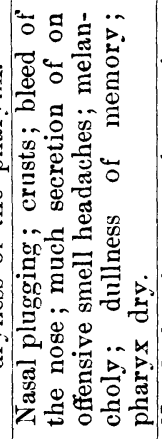 & 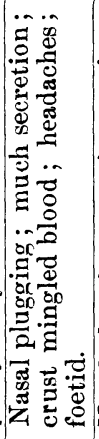 & 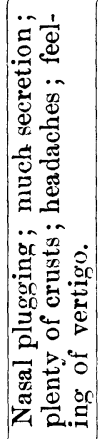 & 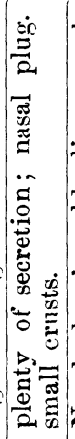 & 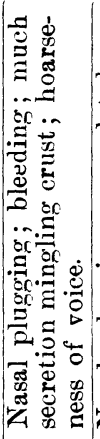 & 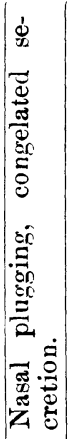 & 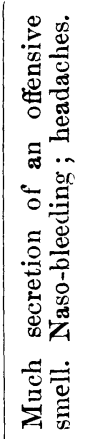 & 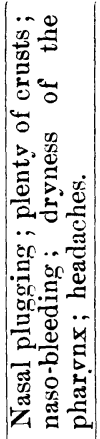 & 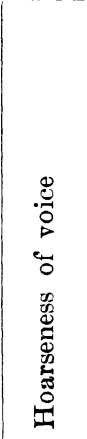 & 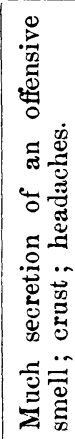 \\
\hline 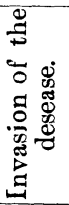 & 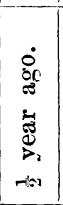 & 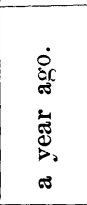 & 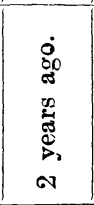 & 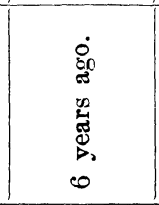 & 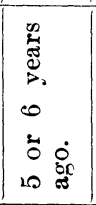 & 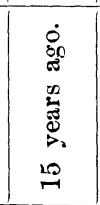 & 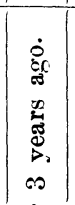 & 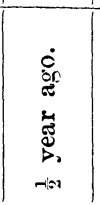 & 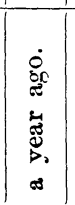 & 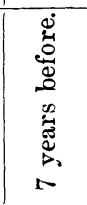 & 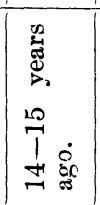 & 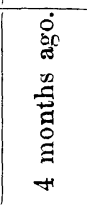 & 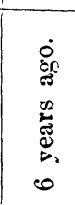 \\
\hline 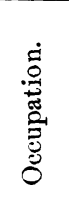 & 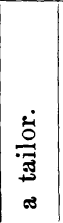 & 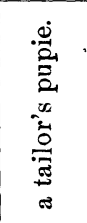 & 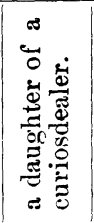 & 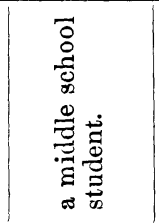 & 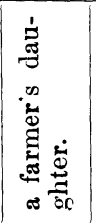 & 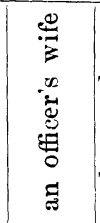 & 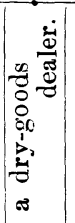 & 荵 & 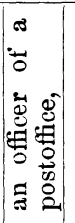 & 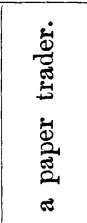 & 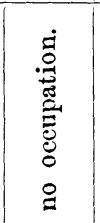 & 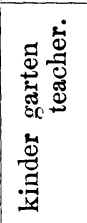 & 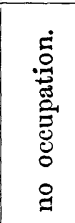 \\
\hline 安 & $\stackrel{2}{2}$ & $\approx$ & $\stackrel{\infty}{\sim}$ & $\stackrel{\infty}{\rightarrow}$ & $\stackrel{\infty}{\sim}$ & ద్ & รి & $\stackrel{2}{\sim}$ & శి & $\stackrel{\rho}{\sim}$ & 아 & సิ & $\stackrel{g}{\rightarrow}$ \\
\hline 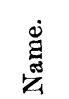 & & & & & & & & & & & & & \\
\hline
\end{tabular}




\begin{tabular}{|c|c|c|c|c|c|c|c|c|c|c|c|c|c|c|}
\hline 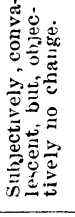 & 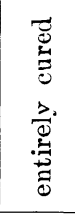 & 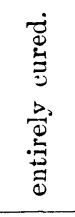 & 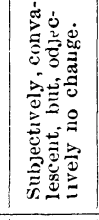 & 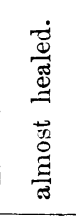 & 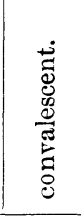 & 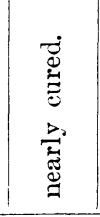 & 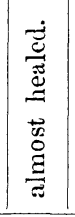 & 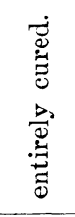 & 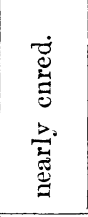 & 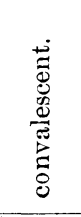 & 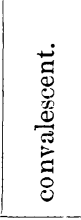 & 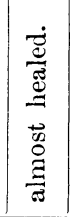 & 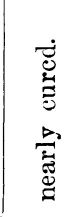 & 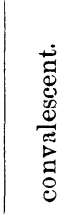 \\
\hline 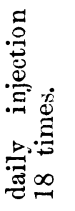 & 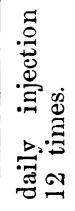 & 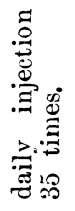 & 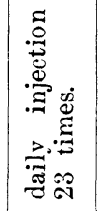 & 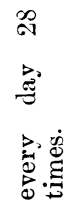 & 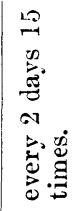 & 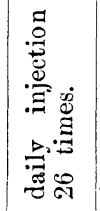 & 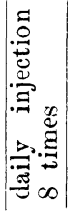 & 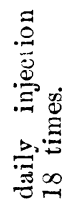 & 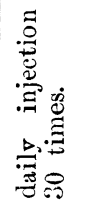 & 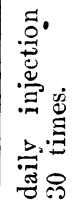 & 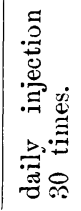 & 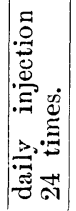 & 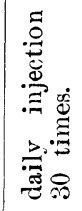 & 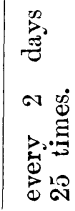 \\
\hline 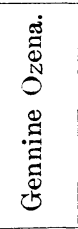 & 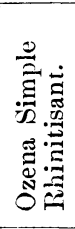 & 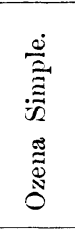 & 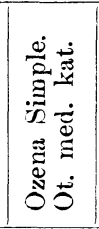 & 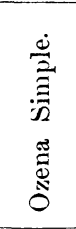 & 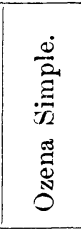 & 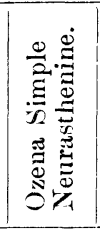 & 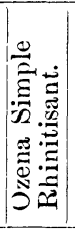 & 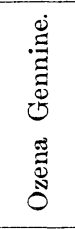 & 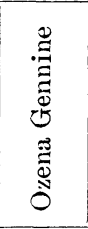 & 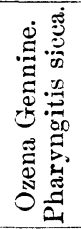 & 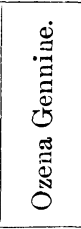 & 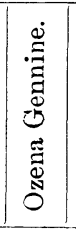 & 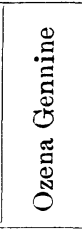 & 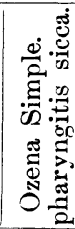 \\
\hline 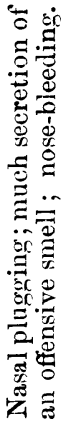 & 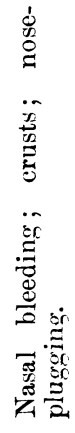 & 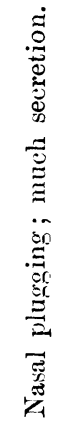 & 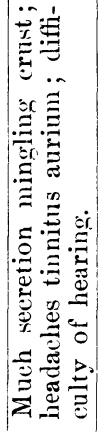 & 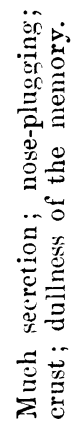 & 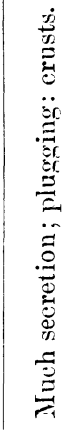 & 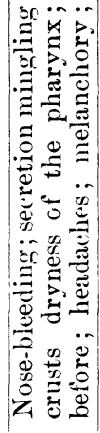 & 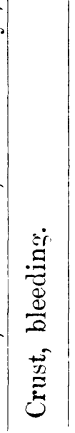 & 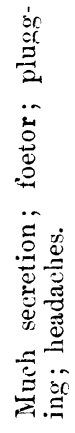 & 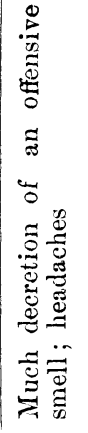 & 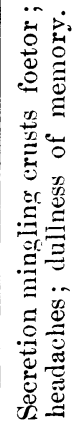 & 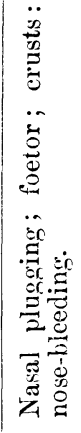 & 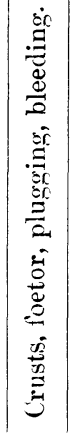 & 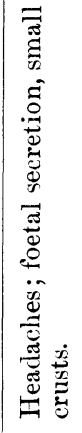 & 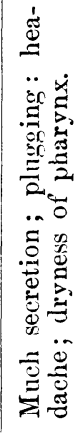 \\
\hline 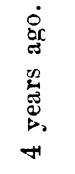 & 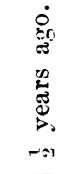 & 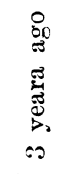 & 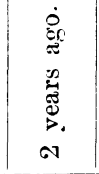 & 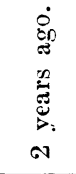 & 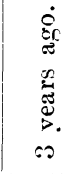 & 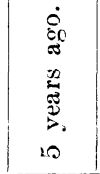 & 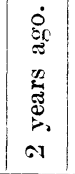 & 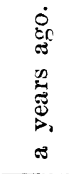 & 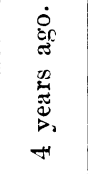 & 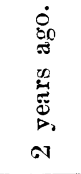 & 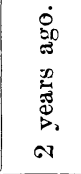 & 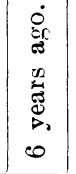 & 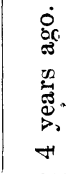 & 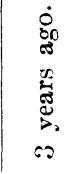 \\
\hline 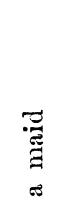 & 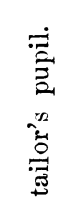 & 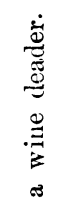 & 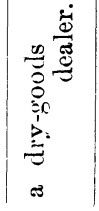 & 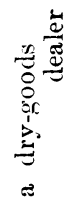 & 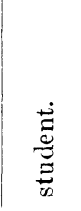 & 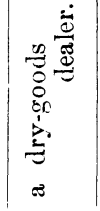 & 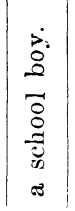 & 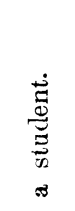 & 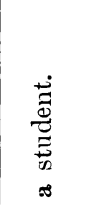 & 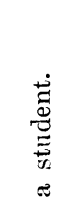 & 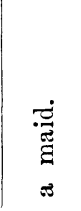 & 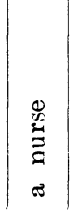 & 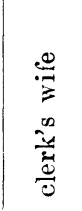 & 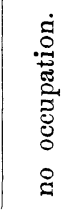 \\
\hline$\stackrel{\sim}{\sim}$ & $\stackrel{\sim}{\rightarrow}$ & $\stackrel{\oplus}{\sim}$ & ลి & $\stackrel{2}{-}$ & $\Leftrightarrow$ & s9 & $\stackrel{\circ}{-}$ & $\stackrel{\rightarrow}{\rightarrow}$ & $\vec{a}$ & $\stackrel{2}{\sim}$ & $\stackrel{\infty}{\sim}$ & ลิ & 19 & $\stackrel{\infty}{\sim}$ \\
\hline
\end{tabular}

